Broadhurst, S. (2017) 'Commissioning an ordinary life', Tizard Learning Disability Review, 22 (1), pp. 38-42.

DOI: https://doi.org/10.1108/TLDR-10-2016-0030

This document is the authors' Accepted Manuscript.

License: https://creativecommons.org/licenses/by-nc-nd/4.0

Available from RADAR: https://radar.brookes.ac.uk/radar/items/0c6033c7-7bec-4fd7-8cf0-8b9eadf753ac/1/

Copyright ( $\subseteq$ and Moral Rights are retained by the author(s) and/ or other copyright owners unless otherwise waved in a license stated or linked to above. A copy can be downloaded for personal non-commercial research or study, without prior permission or charge. This item cannot be reproduced or quoted extensively from without first obtaining permission in writing from the copyright holder(s). The content must not be changed in any way or sold commercially in any format or medium without the formal permission of the copyright holders. 


\title{
Commentary: Commissioning an Ordinary Life
}

\begin{abstract}
Purpose: To review the role and ability of commissioners to implement policy and be transformational leaders.

Approach: The role and ability of commissioners to implement policy is reviewed against the Institute of Public Care's Commissioning Cycle and experience of working with commissioners across the country over the past 29 years.

Findings: Empowering commissioners to be transformational leaders and enabling them to secure good outcomes for people with learning disabilities will require broadening the responsibilities for creating an inclusive society past commissioners of health and social care.

Value: The Transforming Care Programme and the failure to meet targets illustrates that policy implementation in the arena of learning disabilities is still a pertinent issue. This commentary adds to the discussion by highlighting the challenges commissioners face when trying to implement policy and the need to take the conversation about inclusive communities wider than health and social care.
\end{abstract}

\section{Key Words}

Learning Disability, policy implementation, commissioning, ordinary life, inclusive communities.

\section{Author}

Sarah Broadhurst, Principal Consultant and Learning Disability Lead, Institute of Public Care, Oxford Brookes University.

The lack of research on policy implementation makes this paper a welcome addition. Given the events at Winterbourne View and subsequent development of the Transforming Care Programme, policy implementation is a topic of great relevance in the context of learning disabilities. Whilst the research was undertaken prior to Winterbourne View, the author discusses the implications of the findings against the backdrop of the Transforming Care Programme. The fact that government has struggled to reach the targets set on discharging people with learning disabilities from hospital settings, and that Sir Stephen Bubb's Report 'Time to Change - The Challenge Ahead' (2016) highlights the difficulties in implementing policy and good practice, demonstrates that the issues are still very pertinent.

The paper attempts to advance our understanding of policy implementation by identifying key themes that help and hinder. One of the themes discussed throughout the paper, and the theme I have chosen to focus on, is the role of the commissioner.

Some participants felt that commissioners 'misunderstood their role and were unaware of the influence they could exert.' Participants described the relationships between commissioners and providers using the terms 'mistrust; animosity and a lack of transparency'. Commissioners were also thought 'to be lacking in the skills required to successfully lead change.'

At the Institute of Public Care (IPC) we deliver postgraduate level commissioning courses and undertake a wide range of projects with commissioners across the country. In our experience the comments made by participants in the study does 
reflect the reality in some cases but it is by no means true of all commissioners. We do often find people (even within the same organisation) have different perspectives on what commissioning is and sometimes are not aware of or engage in good commissioning practice. Our market shaping work across the country has exposed the nature of the relationships between commissioners and providers which range from constructive to adversarial. The ability of commissioners to be transformational leaders also varies. In our experience though, it depends on the degree to which they are empowered to be so by senior managers.

So what is the role of commissioning and how does it relate to policy implementation? The Department of Health defines commissioning as:

the means by which we secure the best value for local citizens and taxpayers i.e. the best possible health and wellbeing outcomes, and health and social care provision, within the resources available.' (DH, 2013).

Clearly there is no explicit reference to policy implementation in the definition of commissioning. That said one should assume that securing good outcomes will involve implementing good practice guidance and related policy.

But what does good commissioning look like? What does a commissioner need to actually do, to do it well? The IPC commissioning Cycle (Institute of Public Care, 2014) depicted below describes a good practice approach to commissioning. It identifies the stages of commissioning, the activities that should take place and the links to procurement. We would argue that embedded throughout the cycle is the task of implementing policy.

Figure 1: The IPC Commissioning Cycle 


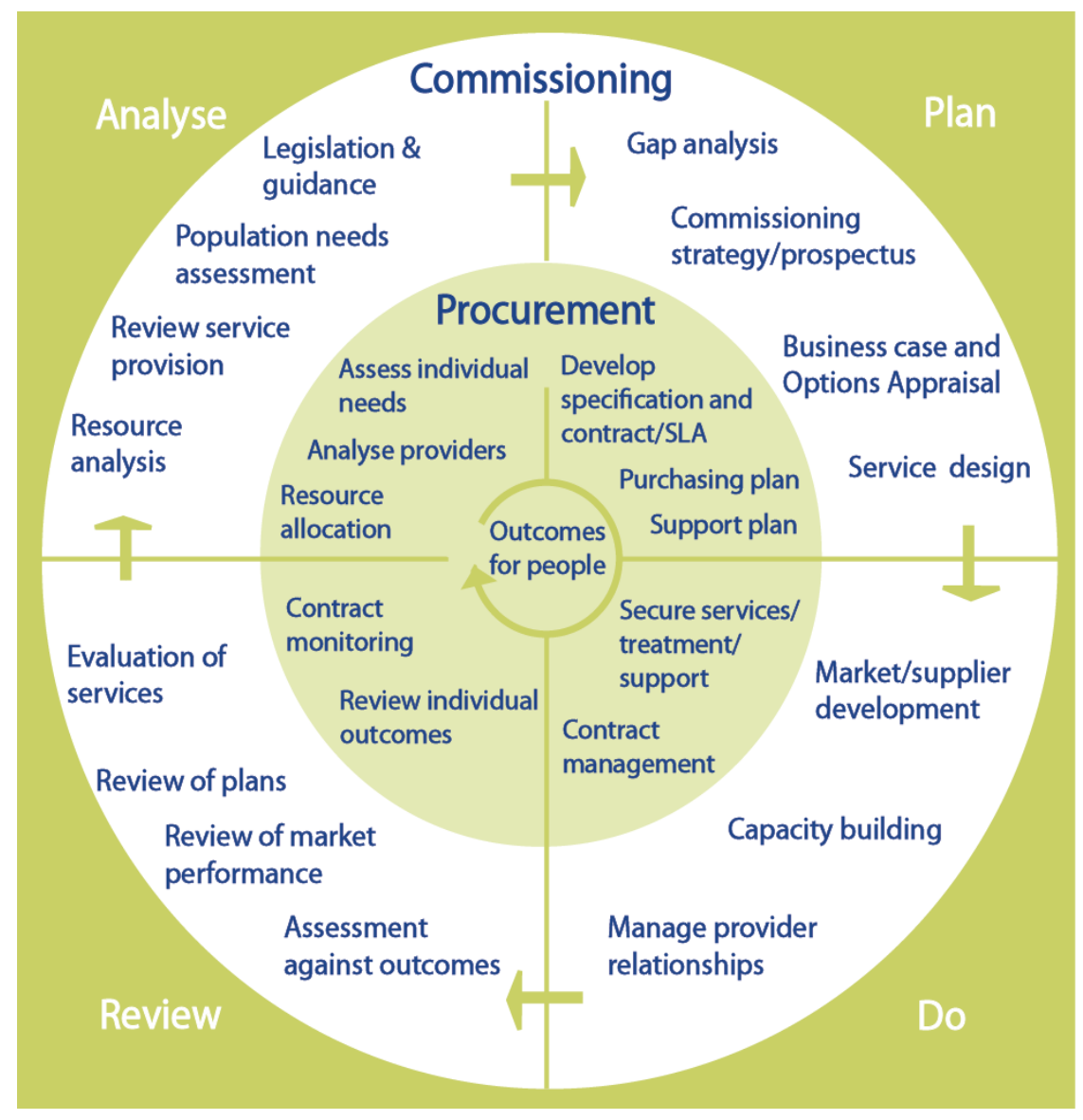

The commissioning cycle can start in either review or analysis. Analysis involves understanding the values and purpose of the agencies involved, the needs they must address, and the environment in which they operate. Some of the activities commissioners should engage in include:

- Clarifying the priorities, and the research and best practice basis for the services.

- Undertaking needs analysis to identify the current and likely future needs of the population.

- Mapping and reviewing services across agencies to understand provider strengths and weaknesses.

- Identifying the resources currently available and agreeing future resources across agencies.

Next is planning. Planning involves identifying the gaps between what is needed and what is available, and planning how these gaps will be addressed. This element of the commissioning cycle involves activities such as:

- Undertaking a gap analysis to review the whole system and identify what is needed in the future.

- Writing a commissioning strategy and designing services to meet needs.

After planning is doing. Doing involves ensuring that the services needed are delivered as planned. Commissioner activities include: 
- Managing the balance of services to reduce risk, i.e. deciding which services should be undertaken in-house and which should be contracted from other providers.

- Developing good communications and effective relationships with existing and potential providers.

- Purchasing new services and de-commissioning services that do not meet the needs of the client group.

The final part of the cycle is reviewing. Reviewing involves monitoring the impact of services. Activities that commissioners should engage in include:

- Pulling together information from individual contracts or service level agreements.

- Developing systems to bring together relevant data on finance, activity and outcomes to review the overall impact of services.

The cycle then begins again at analysis.

Commissioning (the outer circle in the diagram) should drive procurement (the inner circle), not the other way round. Too often commissioners are prevented from commissioning in the way they want due to the mis-application or interpretation of procurement regulations. The Local Government Association (LGA) recently published guidance on procurement in social care 'National Social Care Category Strategy' (LGA, 2015). The strategy references the IPC commissioning model and describes more flexible approaches to procurement in a social care context.

The IPC commissioning cycle illustrates good practice. For commissioners the test is the ability to apply the model in the real world. The world of commissioning is a complex one in which there are many stakeholders and many agendas to satisfy. The approach to commissioning and the culture surrounding it differ between local authorities and clinical commissioning groups. Often bureaucracy involved in decision-making and governance arrangements mean that commissioners must jump through various hoops when commissioning anything. Furthermore, the Care Act (2014) and the need for efficiencies is driving a change to the role of commissioning.

Prior to the Care Act, local authority commissioners were responsible for supporting people eligible for social care to receive good quality commissioned services. The personalisation agenda started to change this. With the implementation of personal budgets and direct payments we began to see commissioners consider how they could ensure that the services people wanted to buy were present in the market. The Care Act builds on this by instilling the principle that commissioners are no longer responsible just for commissioning services, they are responsible for shaping the local care market. The Care Act has also shifted the focus for commissioners from services to outcomes. Commissioners have a responsibility to empower local people and communities to achieve wellbeing outcomes.

Not only has the role of the commissioner widened, we are also seeing increasing demand for learning disability services. Improved healthcare means that life expectancy is increasing for all adults including those with a learning disability. More young people with severe and complex disabilities are surviving into adulthood with a lifelong need for care and support. There is also an increase in the number of people with a moderate learning disability that present with complex needs and dual 
diagnosis eg behaviour related to autism, mental ill health, substance misuse or offending. Therefore, significantly more children and adults with learning disabilities and their families and carers are likely to seek access to health and social care support over the next twenty years. This increase in demand is occurring alongside challenges to the current pattern of services, as public sector spending comes under increasing pressure. The reality is that we simply cannot continue to commission services in the way that we have been doing.

A paper by Parrott (2013) highlighted the need for learning disability commissioners and support planners to start thinking differently. Parrott argues that whilst the concept of personalisation includes a strong emphasis on universal services, social capital, early intervention and prevention, the thinking, culture and practice in relation to meeting the needs of people with a learning disability in different and better ways is underdeveloped. Research indicates that people with learning disabilities want to lead ordinary lives and do the things that most people take for granted. They want to study at college, get a job, have relationships and friendships and enjoy leisure and social activities. The key theme that has run through national policy and good practice guidance for almost forty years is the need to provide services that support people to have healthy, meaningful, ordinary lives. 'The concept that people with a learning disability have the same rights and aspirations as those without learning disabilities is the foundation upon which commissioners and providers should develop services that prevent the need for social care' (Parrott, 2013).

Legislation and guidance reflect these values, and they have gone some way to introducing changes to the context in which care and support for children, adults and their families' occurs. There is an expectation that universal and mainstream services become more inclusive so that people with additional needs, are not perceived as being the responsibility of specialist services only. Indeed the responsibilities for wellbeing outlined in the Care Act are council-wide responsibilities not just the responsibility of social services.

However, the statutory duties and the resources sit mainly in health and social care, which makes it the responsibility of health or social care to achieve outcomes even if those outcomes sit more comfortably in the arena of housing, community safety, or public health. Currently resources are targeted at costly services and those in greatest need. For example, many councils spend significant amounts of the learning disability budget on residential care. In health there is increasing expenditure on acute placements. The problem of targeting resources at those in greatest need is that whilst it meets the short-term demand it does not provide a sustainable solution by meeting needs in different ways. Neither does it uphold the right to have an 'ordinary life' for disabled people and their families.

There is a need to embed an approach to learning disability commissioning that promotes the right to an 'ordinary life'. Such an approach requires creative solutions that empower people with learning disabilities and their families and carers to feel included, valued in society and able to access the same opportunities and facilities as others. These values are explicit in current and previous policy but the flaw has always been to see achieving such outcomes as the responsibility of social services and health alone. The question should not be 'how do we help social care and health commissioners to secure good outcomes by implementing policy?' but 'how do we ensure that other agencies or council departments contribute more'? Securing an 
'ordinary life' for people requires services related to all aspects of life to be inclusive. Social services and health cannot do it on their own. An example of this is ordinary housing.

The author reminds us that: 'access to ordinary housing is a critical success factor as referenced by Mansell and experienced by implementing Transforming Care'. Ensuring that people with learning disabilities have access to ordinary housing requires a wide range of interventions that includes commissioners in social services but also looks towards council housing departments and beyond to landlords and the wider housing market. A second example would be further education, training and employment. One local authority that IPC worked with finally enabled young adults with a learning disability to access the local college only to be told after one term that students without a learning disability were complaining and had started a campaign for separate classes.

Implementing the values espoused in policy is going to require more than knowledgeable learning disability commissioners and or even committed Directors of Social Services. Transformational leadership needs to come from the very top. Elected members and chief executives need to be committed to human rights and inclusion, and to empowering people to lead ordinary lives but this takes political courage. All too often commissioners take transformational service proposals through the appropriate channels to elected members who block them in favour of traditional service models. For example, IPC has seen council members block the closing of costly, building-based day centres that are delivering poor outcomes due to resistance from the local community and the significant, associated political risk of not getting re-elected.

So what would it take to empower commissioners to be transformational leaders and secure good outcomes for people with learning disabilities? Naturally, there are a range of answers but a key aspect is educating the whole council, other stakeholders and even the wider community that people with learning disabilities have the right to an ordinary life and can be supported to live one in a variety of ways that doesn't just involve health or social care. Traditional service models must continue to be challenged because often their very design separates people with learning disabilities from the rest of the community and hence prevents them from living 'ordinary lives'. But such challenge needs to be coupled with a more robust conversation locally and nationally about what it costs to deliver an 'ordinary life', how we design a system that achieves this for increasing numbers of children and adults with learning disabilities and where the resources could come from now and in the future. There is a danger that an 'ordinary life' approach simply restricts commissioners further by becoming a cover for cutting services when it should be a springboard for transformational leadership by increasing collaboration between agencies, providing a vision for more inclusive communities and sparking innovative yet honest discussions about resource generation.

\section{References}

Bubb,S. (2016) Time to Change - The Challenge Ahead. ACEVO: London 
Department of Health (2013) 'Consultation on Specialised Services Specifications and Commissioning Policies 2013/14 - Summary and Response from NHS

England' http://www.england.nhs.uk/wp-content/uploads/2013/07/consult-ssscp-13-

14-sum.pdf

(Accessed 10 July 2016)

Institute of Public Care (2014) Commissioning for Health and Social Care. Sage:

London

Parrott,R. (2013) 'Promoting independence, preventing dependency' Tizard Learning Disability Review 18(4) p161-170

The Local Government Association (2015) National Social Care Category Strategy. Local Government Association: London 